\title{
Functional Attenuation of Ufd11, a 22q11.2 Deletion Syndrome Candidate Gene, Leads to Cardiac Outflow Septation Defects in Chicken Embryos
}

\author{
CHIHIRO YAMAGISHI, BEEREND P. HIERCK, ADRIANA C. GITTENBERGER-DE GROOT, \\ HIROYUKI YAMAGISHI, AND DEEPAK SRIVASTAVA
}

\begin{abstract}
Departments of Pediatrics and Molecular Biology [C.Y., H.Y., D.S.], University of Texas Southwestern Medical Center at Dallas, Dallas, TX, 75390-9148, U.S.A.; and Department of Anatomy and Embryology [B.P.H., A.C.G.], Leiden University Medical Center, Leiden, Netherlands
\end{abstract} \begin{abstract}
ABST
Microdeletion of chromosome $22 \mathrm{q} 11.2$ is commonly associ-
ated with congenital cardiovascular defects that involve development of cranial neural crest cells (NCC) that emigrate through the pharyngeal arches. UFD1l is one of several candidate genes for $22 \mathrm{q} 11.2$ deletion syndrome (22q11DS). UFD1l encodes a protein whose yeast counterpart is involved in a ubiquitindependent proteolytic degradation pathway; however, the role of UFD1L in NCC development remains unknown. Mouse embryos that lack Ufdll die before organogenesis. We have therefore studied the function of Ufd11 in the chick system. Chick Ufd1l encoded a 307-amino acid protein that was highly conserved with mouse and human UFD1L. Chick Ufd11 was expressed in the developing neural tube, NCC, and mesenchyme of the head and pharyngeal arch structures, as well as in the conotruncal region (cardiac outflow tract), consistent with the clinical features of 22q11DS. To determine loss-of-function effects of chick Ufd11 in NCC, we infected cardiac NCC with a retrovirus
\end{abstract}

expressing antisense Ufd11 transcripts in chick embryos before their migration. Morphologic analysis of infected embryos at a later developmental stage demonstrated that functional attenuation of chick Ufd11 in cardiac NCC resulted in an increased incidence of conotruncal septation defects. These data suggest that Ufd11 may play a role in cardiac NCC during conotruncal septation. (Pediatr Res 53: 546-553, 2003)

$\quad$ Abbreviations
CVD, cardiovascular defects
del.22q11, microdeletion of chromosome 22q11.2
ET $_{\text {A }}$, endothelin receptor A
HH, Hamburger and Hamilton
NCC, neural crest cells
VSD, ventricular septal defect
22q11DS, 22q11.2 deletion syndrome

Monoallelic microdeletion of chromosome 22q11.2 (del.22q11) is the most common human chromosomal deletion and results in the 22q11.2 deletion syndrome (22q11DS), with an estimated frequency of 1 in 4000-5000 births (1). 22q11DS encompasses three independently established syndromes, including DiGeorge syndrome, velo-cardio-facial syndrome, and conotruncal anomaly face syndrome, and manifests a variety of

Received June 13, 2002; accepted December 4, 2002

Correspondence: Deepak Srivastava, M.D., Departments of Pediatrics and Molecular Biology, University of Texas, Southwestern Medical Center at Dallas, 6000 Harry Hines Boulevard, Dallas, TX 75390-9148, U.S.A.; e-mail: Deepak.Srivastava@UTSouthwestern.edu

This work was supported by NHLBI/NIH, March of Dimes and Smile Train Inc., and NHS grant 1998B82.

DOI: 10.1203/01.PDR.0000055765.11310.E3 features, including craniofacial and cardiovascular defects (CVD) and behavioral and psychiatric disorders (2-4). $22 q 11 D S$ is associated with specific types of CVD that are characterized as malformations of the conotruncus (outflow tract of the heart) or the aortic arch, including persistent truncus arteriosus, tetralogy of Fallot, and interrupted aortic arch, type B (5). The craniofacial defects and CVD in 22q11DS result from defects of embryonic structures populated by migrating cranial and cardiac neural crest cells (NCC) that originate from the caudal hindbrain $(6,7)$. Ablation of cardiac NCC in chick embryos results in persistent truncus arteriosus, aortic arch malformations, and hypoplasia of thymus and parathyroid glands similar to that observed in patients with 22q11DS $(6,7)$. This suggests that studies on candidate genes in the $22 q 11.2$ 
region that are involved in the development of cardiac NCC may provide insight into the molecular mechanisms underlying the 22q11DS and its associated CVD.

More than $90 \%$ of patients with 22 q11DS have a similar del.22q11, commonly spanning 1.5-3 megabases in size (8). More than 30 genes have been identified in the deleted region. Recent studies show that haploinsufficiency of $T b x l$, one of the genes in this region, is likely to be the major determinant of aortic arch defects in patients with 22q11DS (9-11). However, no single gene mutation, including that of $T B X 1$, that results in the 22q11DS phenotype has yet been detected $(12,13)$. Our screen for mouse genes dependent on dHAND, a transcription factor implicated in NCC development, previously identified Ufdll, whose human ortholog had been mapped to 22q11.2 $(14,15)$. UFD1L encodes a highly conserved protein from yeast to human that is involved in the degradation of ubiquitinated proteins. Mouse UfdIl was expressed in many embryonic tissues affected in patients with 22q11DS, including the pharyngeal arches, palatal precursors, the frontonasal region, telencephalon, and the cardiac outflow tract. Human UFD1L was deleted in $>180$ patients studied with 22q11DS (15). A smaller deletion of exon 1 to 3 of UFDIL and its neighboring gene, $C D C 45$, which encodes a putative cell cycle regulating protein, was found in one individual with the phenotype of 22q11DS. These results suggest that UFD1L may be implicated in some features of 22q11DS, although the very early lethality of mice that lack $U f d 1 l$ precludes an understanding of the role of UFD1L in cardiac NCC development (16).

The avian system is well established to study NCC development, as gene constructs can be specifically introduced into the chick NCC lineage using a replication-incompetent retrovirus system (17). To take advantage of the avian system, we cloned the chick ortholog of UFD1L and performed expression and functional analyses of chick Ufd11 during embryogenesis, focusing on cardiac NCC development. Chick Ufd1l was expressed in a variety of developing tissues with enhanced expression in the cardiac outflow tract and neural crest-derived mesenchyme of pharyngeal arches and aortic arch arteries, similar to mouse Ufd1l. Attenuation of chick Ufd1l expression in premigratory cardiac NCC resulted in an increased number of conotruncal septation defects. These data suggest that Ufd11 may play a role in the development of cardiac NCC that contribute to conotruncal septation.

\section{METHODS}

Cloning of chick Ufd1l. A stage 12-15 chick embryo library in lambdaZAPII was screened according to the manufacturer's instructions (Stratagene), with chick Ufd11 partial cDNA (741bp) that was obtained from Hamburger and Hamilton (HH) stage 12 chick total RNA by reverse-transcribed PCR. Approximately $1 \mu \mathrm{g}$ of total RNA was reverse transcribed using M-MuLV transcriptase (Roche). One microliter of the first-strand cDNA produced was used as template for PCR reactions using specific oligonucleotide amplimers (5'GGAGAAAGGAGGGAAGATAA-3', 5'-GCTTCATCCTCTTCAACCTT-3') derived from mouse Ufd11 cDNA. 5' rapid amplification of cDNA ends was then performed to obtain full-length cDNA according to manufacture's instructions (Clontech).

Northern analysis. Total RNA from several chick tissues at embryonic day 18 was electrophoresed, transferred to a nylon membrane, and hybridized with a ${ }^{32} \mathrm{P}$-labeled full-length chick Ufd11 cDNA probe. Hybridization was performed in Rapidhyb buffer (Amersham) at $65^{\circ} \mathrm{C}$ overnight and washed with 2 $\times$ salt-sodium chloride $/ 0.1 \%$ SDS at room temperature for 10 min and $1 x$ salt-sodium phosphate-EDTA $/ 1 \% \operatorname{SDS}$ at $65^{\circ} \mathrm{C}$ for 15 min. Nylon membrane was exposed to x-ray film (Kodak).

Collection of chick embryos and primary NCC culture experiments. Fertilized eggs were incubated at $37^{\circ} \mathrm{C}$ to obtain chick embryos of $\mathrm{HH}$ stage 10-26. The cranial neural fold from the otic vesicle to somite 3 of stage 9-11 chick embryos was dissected and treated with $0.5 \mathrm{mg} / \mathrm{mL}$ collagenase type II in PBS at $37^{\circ} \mathrm{C}$ for $2-3 \mathrm{~min}$ to remove the mesenchyme surrounding the neural tube. The isolated neural tube was washed in Dulbecco's modified Eagle's medium including $10 \%$ fetal bovine serum, then placed on gelatin-coated culture plates. The dissected neural tubes were cultured at $37^{\circ} \mathrm{C}$ for 36-48 h in Dulbecco's modified Eagle's medium including $10 \%$ fetal bovine serum to allow NCC to migrate from the neural tubes onto culture plates. NCC were fixed with $4 \%$ paraformaldehyde/PBS. In situ hybridization and immunohistochemistry were subsequently performed. All experimental procedures were performed according to the current local guidelines for animal experiments in the University of Texas Southwestern Medical Center and Leiden University Medical Center.

$\boldsymbol{R N A}$ in situ hybridization. RNA in situ hybridization of chick embryos and cultured NCC was performed as previously described (18) with digoxigenin-labeled Ufd1l riboprobes synthesized from a 741-bp fragment of chick Ufd11 cDNA. Briefly, chick embryos of varying stages were isolated, and the pericardium was removed. Embryos were fixed in 4\% paraformaldehyde $/ \mathrm{PBS}$ at $4^{\circ} \mathrm{C}$ overnight. Embryos were treated with proteinase $\mathrm{K}(30 \mu \mathrm{g} / \mathrm{mL})$ for $3-20 \mathrm{~min}$ at room temperature depending on their stage of development. Prehybridization was performed at $61{ }^{\circ} \mathrm{C}$ for $3 \mathrm{~h}$ in solution containing $50 \%$ formamide, $4 \times$ salt-sodium chloride, $1 \times$ Denhardt's solution, 500 $\mu \mathrm{g} / \mathrm{mL}$ salmon sperm DNA, $250 \mu \mathrm{g} / \mathrm{mL}$ yeast tRNA, and $10 \%$ dextran sulfate. Hybridization was performed in the same solution for $18 \mathrm{~h}$. After a series of washes, embryos were treated in $2 \%$ blocking solution for $2 \mathrm{~h}$ and incubated with antidigoxigenin antibody for $1 \mathrm{~h}$ at room temperature. Color reaction was performed at room temperature in substrate color reaction mixture for $12-18 \mathrm{~h}$ and terminated by fixing embryos in $4 \%$ paraformaldehyde $/ 0.1 \%$ glutaraldehyde.

Radioactive in situ hybridization was performed using ${ }^{35} \mathrm{~S}-$ labeled antisense riboprobes synthesized with T7 or SP6 RNA polymerase (MAXIscript, Ambion Inc.) from chicken dHAND or neuropilin-1 full-length cDNA, respectively. Paraffinembedded coronal sections of HH stage 18 control embryos and antisense Ufd1l-infected embryos were hybridized with probes as previously described (18). Plasmids for dHAND and neuropilin-1 riboprobe are available upon request.

Fixed NCC were treated with proteinase $\mathrm{K}(30 \mu \mathrm{g} / \mathrm{mL})$ for 5 min at $37^{\circ} \mathrm{C}$. After postfixation with $4 \%$ paraformaldehyde/ 
PBS, cells were dehydrated in methanol. In situ hybridization was performed at $61^{\circ} \mathrm{C}$ for $18 \mathrm{~h}$ as described above.

Immunocytochemistry. For immunocytochemistry, fixed and dehydrated $\mathrm{NCC}$ were incubated with $3 \% \mathrm{H}_{2} \mathrm{O}_{2}$ for $30 \mathrm{~min}$ at room temperature. After rehydration, cells were incubated in blocking solution $[3 \%$ BSA, $0.1 \%$ Igepal (Sigma Chemical Co.) in PBS] at room temperature for $30 \mathrm{~min}$ and then incubated in primary antibody, anti-HNK-1/N-CAM (Sigma Chemical Co.; 1:60), at room temperature for $60 \mathrm{~min}$. After several washes in PBS, conjugated secondary antibody [antimouse IgM (1:50)] was applied to the cells and incubated at room temperature for $60 \mathrm{~min}$. The cells were then incubated in developing solution $[0.03 \% 3$-3'-diaminobenzidine tetrahydrochloride (Sigma Chemical Co.) $-0.1 \%$ TritonX in PBS] at room temperature for $10 \mathrm{~min}$. Color reaction was performed in $0.03 \% \mathrm{H}_{2} \mathrm{O}_{2}$ at room temperature for $10 \mathrm{~min}$. After several washes in PBS, cells were fixed with $4 \%$ paraformaldehyde/ $0.1 \%$ glutaraldehyde for $12-24 \mathrm{~h}$.

In vitro transcription and translation. The full-length chick Ufd11 cDNA was cloned in the sense and antisense direction into pBluescript plasmids. Mouse endothelin receptor $\mathrm{A}\left(\mathrm{ET}_{\mathrm{A}}\right)$ was also cloned in antisense direction into pBluescript plasmids as a control. All plasmids were linearized with SmaI for in vitro transcription and translation reactions using TNTcoupled Reticulocyte Lysate System (Promega) with T7 RNA polymerase. One microgram of sense cUfd1l plasmid and antisense cUfd1l or $\mathrm{ET}_{\mathrm{A}}$ plasmid were mixed together in the same tube for transcription and translation. A sense cUfd11 plasmid and pBluescript plasmid mixture was performed simultaneously as a control. Translated products were labeled with $\left[{ }^{35} \mathrm{~S}\right]$ methionine (Amersham) and determined by SDSPAGE and autoradiography. The signals were quantified using ImageQuant software (Molecular Dynamics).

Retrovirus infection of chick embryos. The full-length chick Ufd1l cDNA was cloned in the sense and antisense direction into the proretroviral pCXIZ vector (gift from Dr. Takashi Mikawa). All retroviral constructs were stably transfected to the D17.2G helper cell line for virus production. In vivo infection of premigrating $\mathrm{NCC}$ in chick embryos was performed at HH stage $9-11$ as described previously $(19,20)$. The embryos were allowed to develop in ovo until $\mathrm{HH}$ stage 31-32 and then were harvested and fixed with 4\% paraformaldehyde for histologic analysis. HH stage 18 embryos were also harvested for section in situ hybridization using dHAND and neuropilin-1 riboprobes.

In vitro infection was performed on neural tube dissected from $\mathrm{HH}$ stage $9-11$ as described above. After NCC migration, $\beta$-galactosidase activity was detected by using X-gal as described previously (21).

Histology. Embryos were embedded in paraffin, and serial transverse sections were obtained. The transverse sections of embryos after retrovirus infection or control embryos were stained with hematoxylin and eosin.

\section{RESULTS}

Chick Ufd1l $\boldsymbol{c D N A}$. The largest cDNA obtained of chick Ufdll by library screening followed by 5 rapid amplification of
cDNA ends contained 1026 nucleotides. Chick Ufd1l was predicted to encode a 307-amino acid protein and was highly conserved with its murine (94\% identical, 96\% similar) and human (94\% identical, 96\% similar) counterparts (Fig. 1A). Although the previously cloned human UFD1L protein (as translated from cDNA, GenBank accession number U64444) (14) showed a tandem repetition of a 36-amino acid domain that was present in the yeast, chicken, and mouse as a single copy, the protein sequences predicted from all human UFD1L cDNAs that we cloned (GenBank accession number
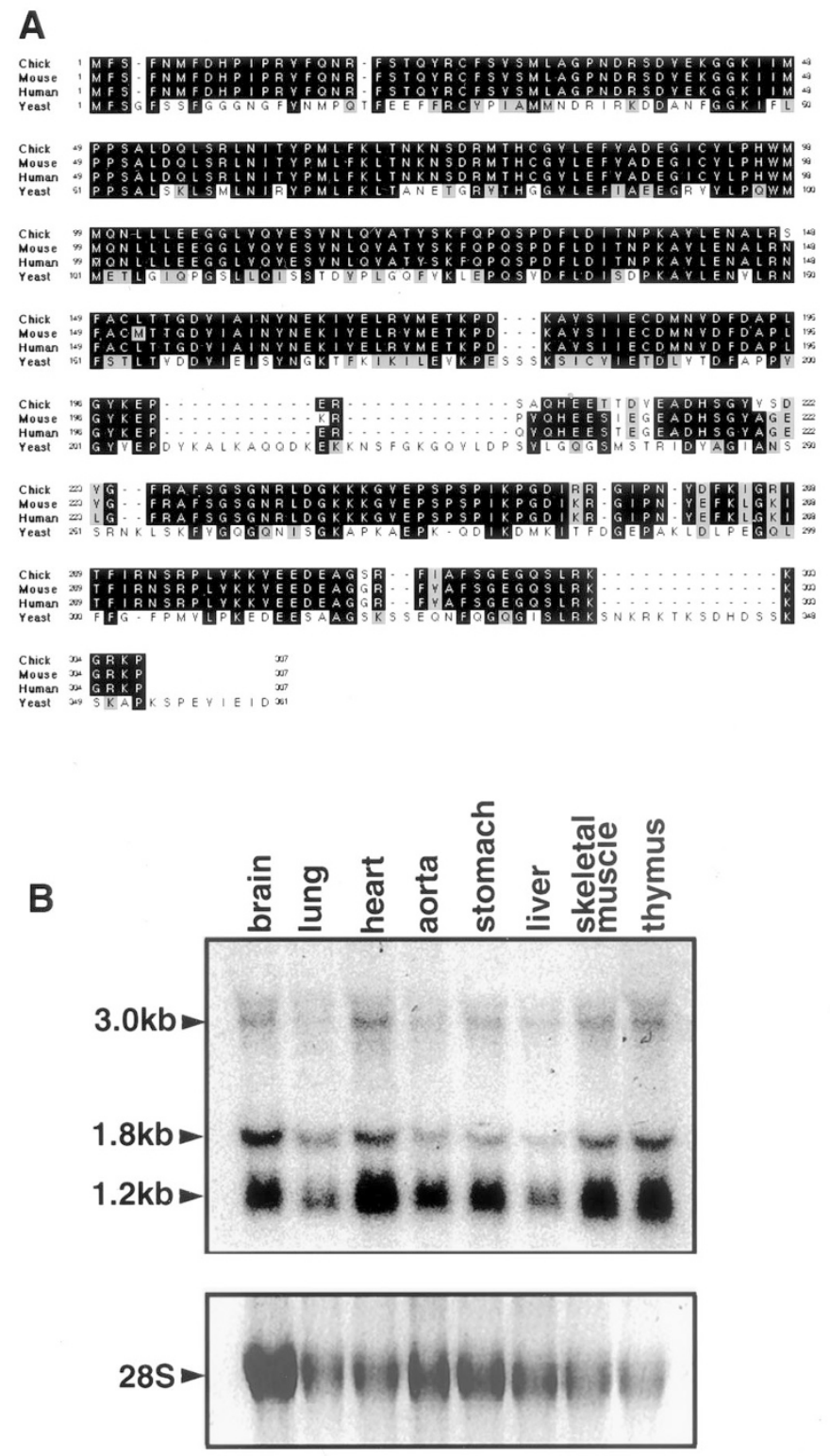

Figure 1. Sequence and expression of chick Ufd11. $A$, Sequence alignment of full-length chick Ufd11 with mouse, human, and yeast Ufd11. Amino acid residues that are identical or similar are shaded in black or gray, respectively. Chick Ufd1l encodes a 307-amino acid protein and is highly conserved with its murine (94\% identical, 96\% similar) and human (94\% identical, 96\% similar) counterparts. It was $36 \%$ identical and $50 \%$ similar to yeast Ufd1. B, Northern blot analysis of chick Ufd11 in embryonic day 18 tissues. mRNA transcripts $(1.2,1.8$, and $3.0 \mathrm{~kb})$ were present in all tissues examined. The expression levels of chick Ufd11 in brain, heart, skeletal muscle, and thymus were higher than in other tissues. 
AY101594) did not contain such a domain and were more similar to those of other species. Chick Ufd11 was also $36 \%$ identical and $50 \%$ similar to yeast Ufd1. Nucleotide and protein sequences of chick Ufd1l are available at NCBI (GenBank accession number AF407671).

Expression pattern of chick Ufd1l. Northern blot analysis of total RNA from several chick tissues at embryonic day 18 was performed using full-length chick Ufd1l cDNA as a probe. mRNA transcripts $(1.2,1.8$, and $3.0 \mathrm{~kb})$ were present in all tissues examined and possibly represented alternatively spliced forms (Fig. 1B). The expression level of chick Ufd11 in each tissue was variable, with expression in brain, heart, skeletal muscle, and thymus relatively higher than in other tissues.

To determine the expression pattern of chick Ufdll during embryogenesis, in situ hybridization analysis was performed. Chick Ufd1l was detectable by stage 7 in the neural plate (data not shown). At stage 10, as the neural tube and somites formed, expression throughout the neural tube was apparent (Fig. 2A). At later stages, chick Ufdll was expressed in many tissues, with marked expression in the head, pharyngeal arches, frontonasal region, neural tube, and limb buds (Fig. 2, B and C). Whole-mount in situ hybridization on the heart dissected from embryos at stage 26 , when conotruncal septation takes place, demonstrated strong expression of chick $U f d 1 l$ in the conotruncal region of the heart and in emerging aortic arch arteries (Fig.
2D). The expression of chick Ufd1l in the neural tube and mesenchymal cells along the pharyngeal arch arteries was detected in transverse sections through chick embryos after whole-mount in situ hybridization (Fig. 2, E and F). The overall embryonic expression pattern of chick Ufd1l was similar to that of mouse $(14,15)$ and consistent with some of the clinical features of 22q11DS.

To determine whether chick Ufd11 was expressed in migrating NCC, we examined primary chick NCC cultures. NCC that had migrated off chick neural tube in culture exhibited normal expression of the avian NCC marker HNK-1 by immunocytochemistry (Fig. 3A). In situ hybridization in the cultured NCC demonstrated chick Ufd1l expression in the migrating NCC, consistent with the result of whole-mount in situ hybridization analysis on embryos (Fig. 3, B and C).

Functional attenuation of chick Ufd1l by retroviral infection. To investigate the functional role of chick Ufd1l in cardiac NCC, we used a well-established gene introduction system in chick NCC using a replication-incompetent retrovirus (17). To study loss of function effects in vivo, we prepared a Ufd11 antisense retroviral vector that would generate Ufd11 antisense transcripts. To determine first whether the Ufd11 antisense transcripts might interfere with normal translation of Ufd11 sense transcripts, we performed in vitro transcription and translation experiments. As shown in Figure 4, the protein
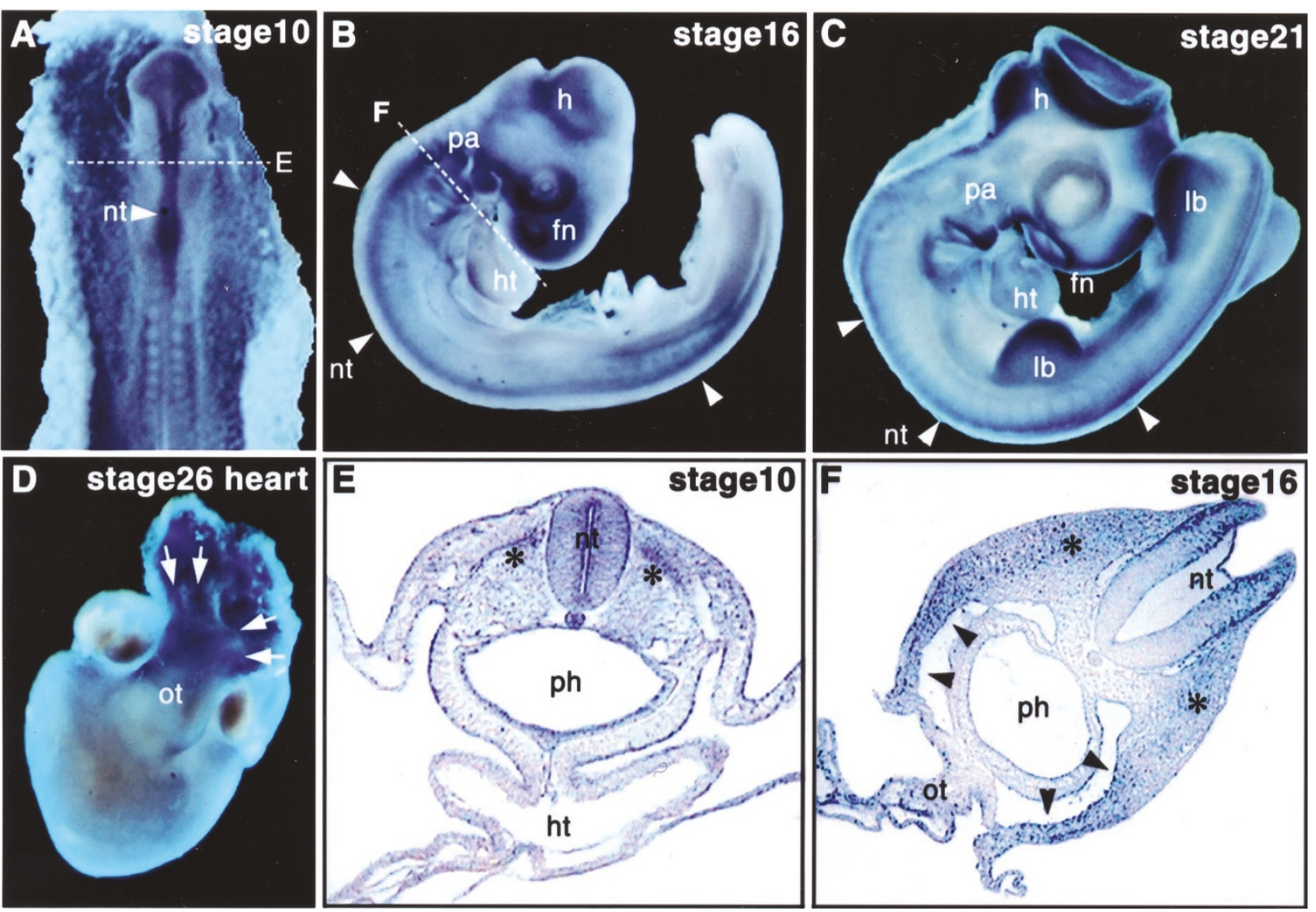

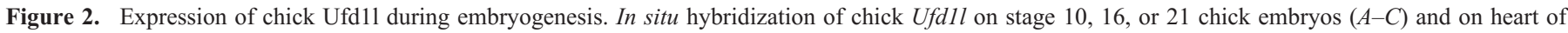

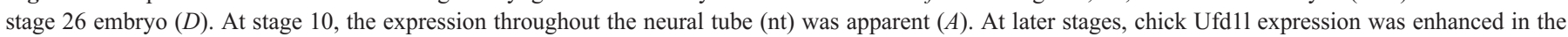

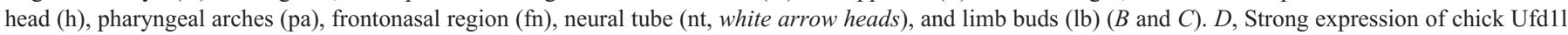

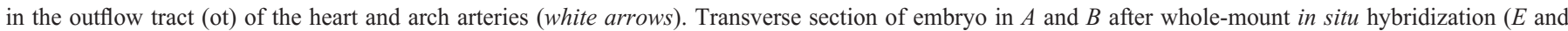

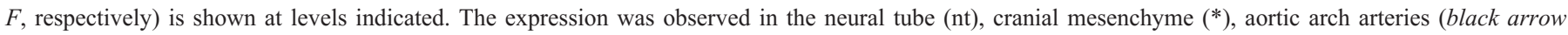
heads), and outflow tract (ot) ( $E$ and $F$ ). ph, pharynx; ht, heart. 

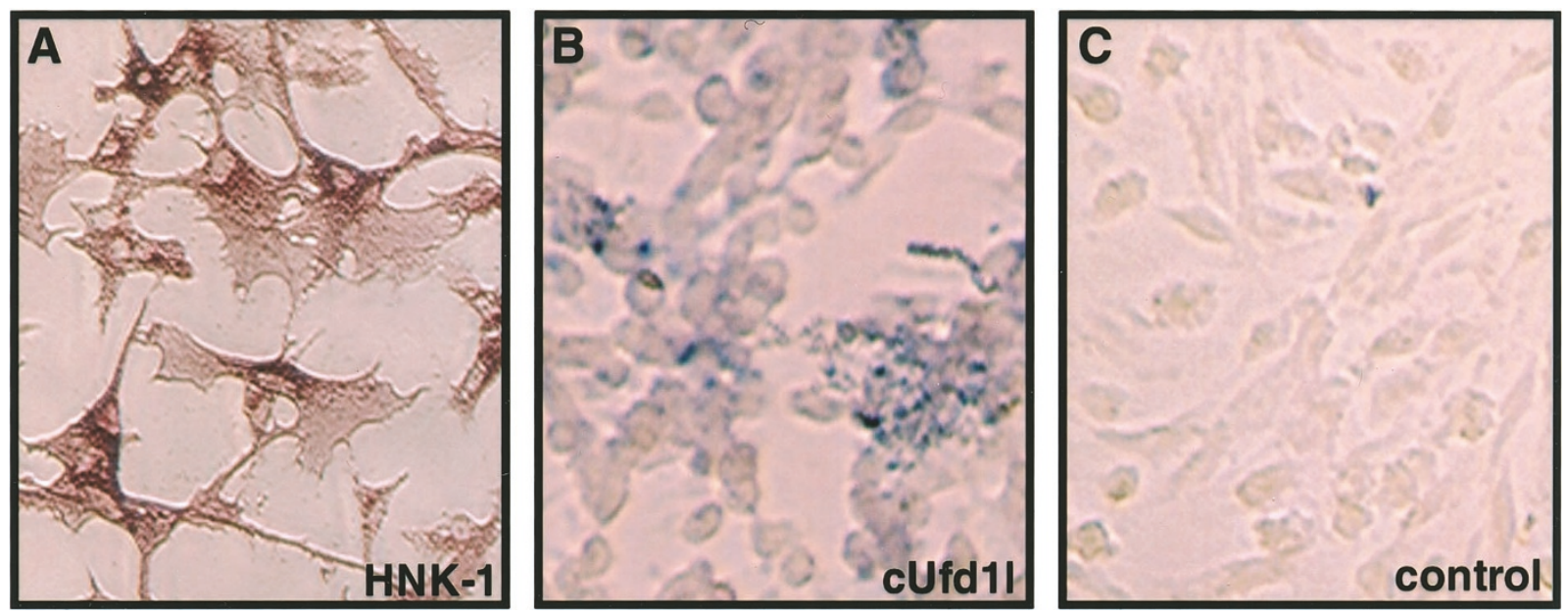

Figure 3. Chick $U f d 1 l$ is expressed in primary neural crest culture. $A, \mathrm{HNK}-1$, as a NCC marker, was detected by immunocytochemistry in primary neural crest cultured cells. $B$, Chick Ufd11 transcripts were detected by antisense mRNA in situ hybridization in primary cultured cells. $C$, In situ hybridization with sense Ufd11 riboprobe as control.
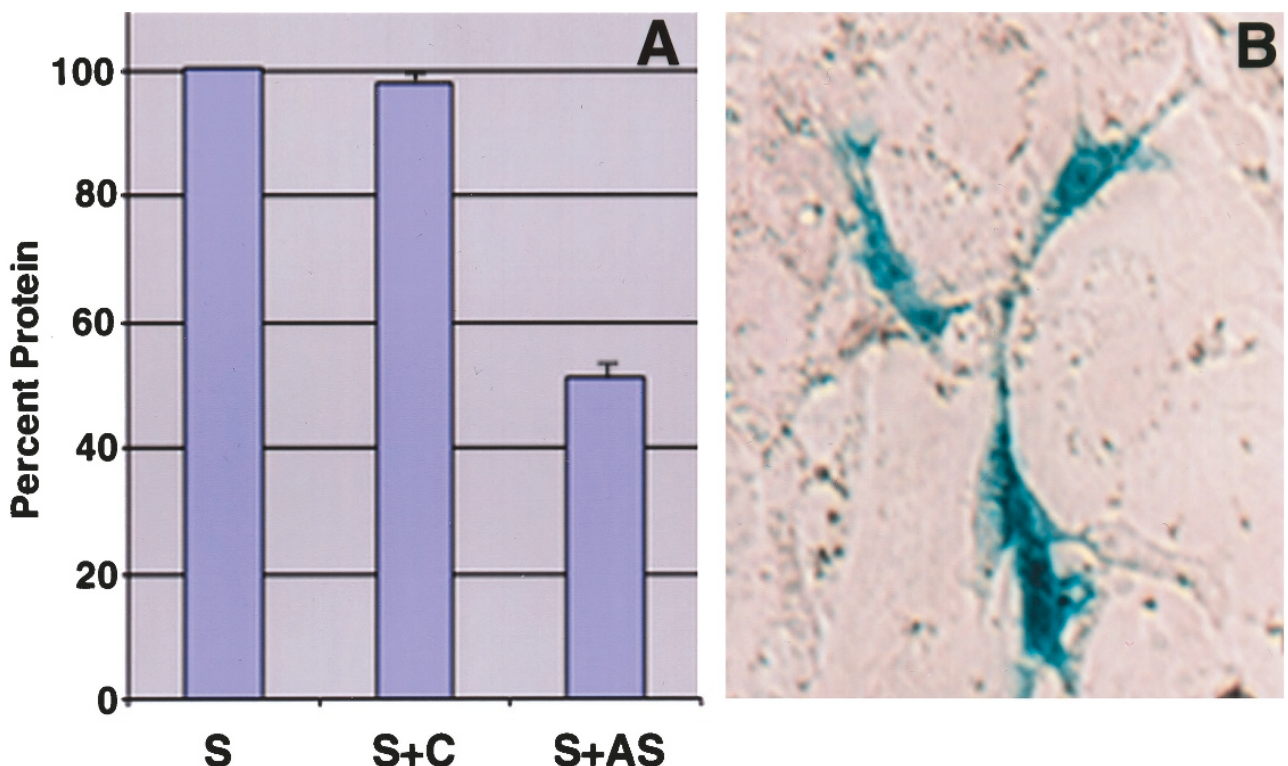

Figure 4. Antisense chick Ufd11 transcripts can attenuate chick Ufd11 protein expression. A, Quantitative analysis of in vitro transcription and translation reveals a 54\% reduction in Ufd11 protein when Ufd11 sense (S) and antisense (AS) transcripts were co-incubated compared with S alone or S with a control (C) antisense $\left(\mathrm{ET}_{\mathrm{A}}\right)$. The expression of $\mathrm{ET}_{\mathrm{A}}$ antisense transcripts did not affect protein expression of chick Ufd11. $B$, Primary NCC culture after neural tube infection with retrovirus containing the AS Ufd11 expression construct linked to $\beta$-galactosidase. Survival and migration of infected cells (blue) were unaffected.

expression of chick Ufd11 was reduced $\sim 50 \%$ by expression of the antisense chick Ufd1l transcript. The expression of control $\left(\mathrm{ET}_{\mathrm{A}}\right)$ antisense transcripts did not affect the protein expression of chick Ufd11, suggesting that the effect of antisense chick Ufd11 introduction was specific for the reduction of chick Ufd11 protein expression. To determine whether cells infected with the Ufd1l antisense vector had a nonspecific survival defect, we performed primary neural crest culture from neural tube infected with the Ufd1l antisense retrovirus. Retrovirusinfected cells were marked in blue by $\beta$-galactosidase staining, and we found that their survival was unaffected by Ufd11 antisense transcripts (Fig. 4B).

For determining the functional role played by chick Ufd 11 in cardiac NCC, the rostral neural tube was infected with retrovirus containing the antisense Ufd11 expression construct be- fore NCC migration. By examining the hearts of a number of embryos at HH stage 31-32, $6 \mathrm{~d}$ after the retroviral infection, we found a significant $(p<0.05)$ increase in septal defects (nine of 12) compared with control embryos (two of 12 and zero of 12 , respectively) that were infected with retrovirus containing an empty vector (Fig. 5, A-F). Five of 12 experimental embryos had defects of the upper portion of the ventricular septum (VSD; Fig. 5, B and E). An additional four of 12 embryos had VSD and defects in septation of the aorta and pulmonary artery (conotruncal septal defects; Fig. 5, C and F). This combination was never observed in control embryos $(p<$ $0.05)$, whereas isolated VSD were observed in two of 12 control embryos. Examination of the aortic arch in all embryos failed to detect any defects at this stage. Results are summarized in Table 1. 
Control

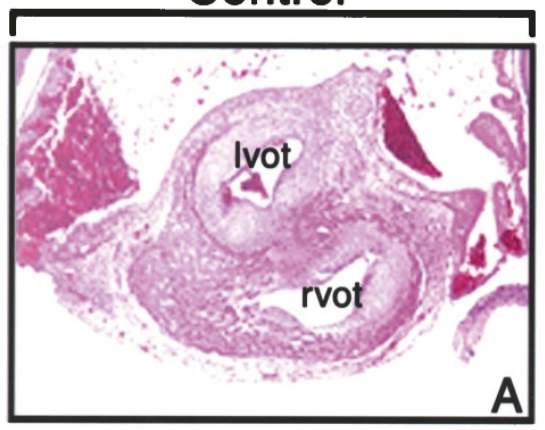

A
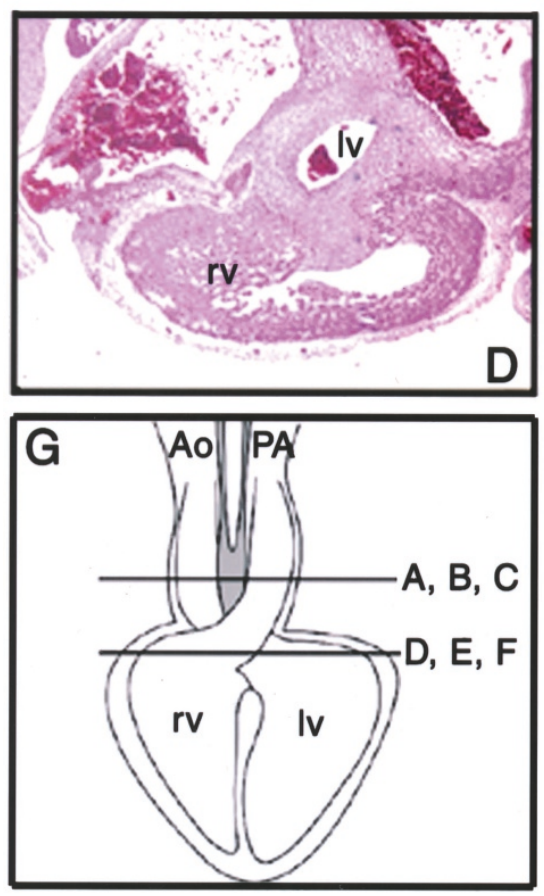

cUfd1l AS infected embryos
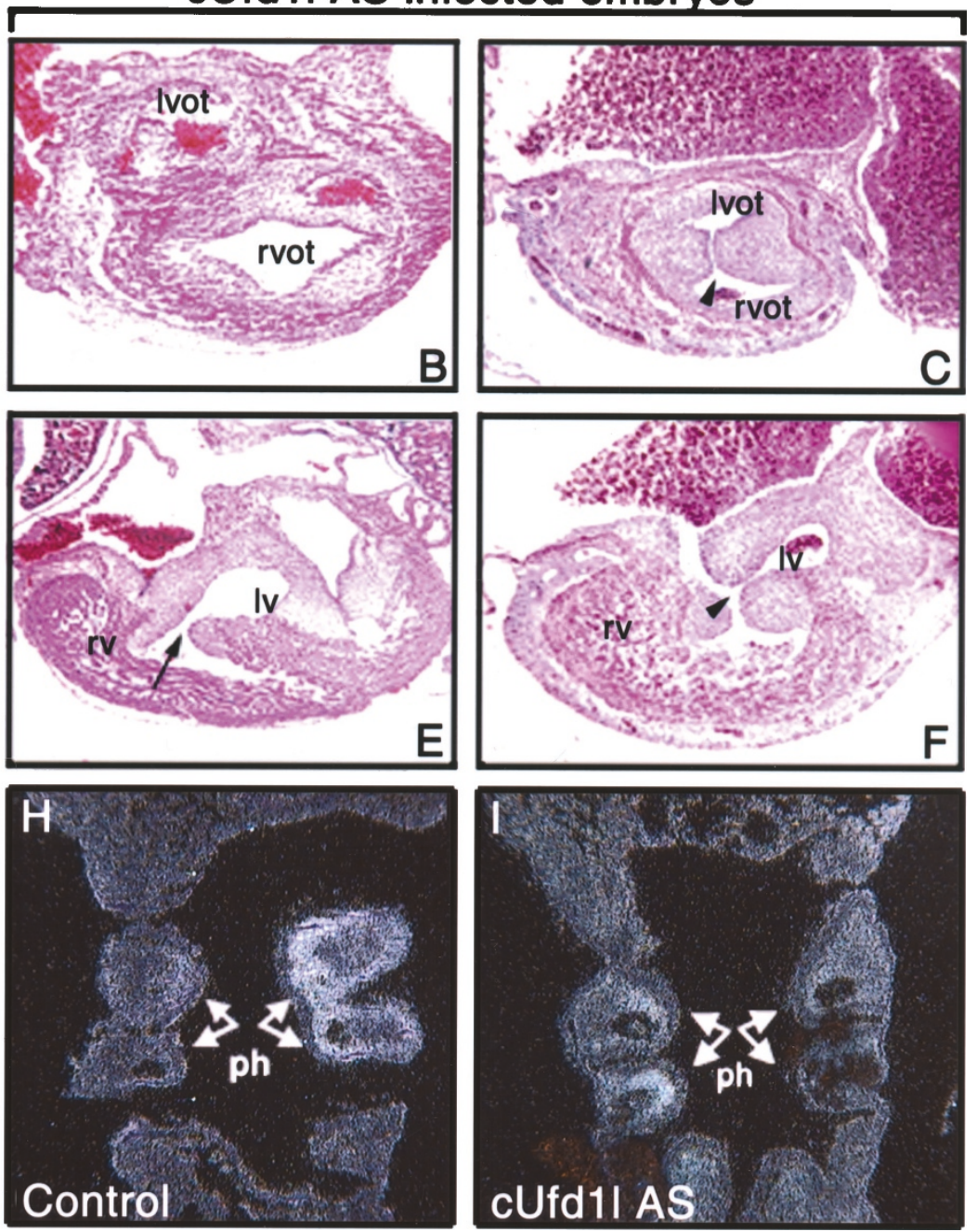

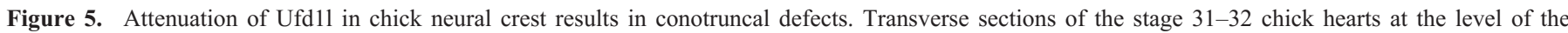

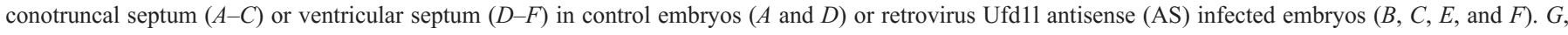

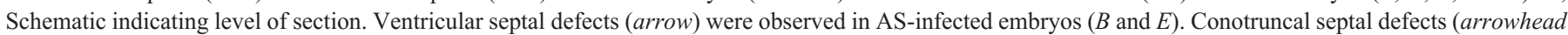

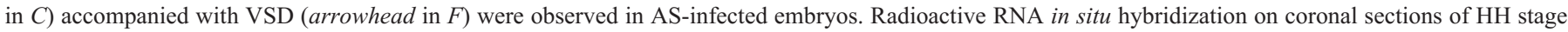

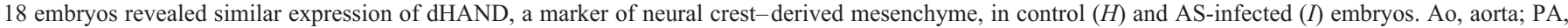
pulmonary artery; lv, left ventricle; lvot, left ventricular outflow tract; rv, right ventricle; rvot, right ventricular outflow tract; ph, pharyngeal arch.

Table 1. $c$ Ufd11 AS retrovirus-infected embryos display cardiac outflow tract defects

\begin{tabular}{ccc}
\hline & cUfd11 AS & Control vector \\
\hline Septal defects & $75 \%(9 / 12)^{*}$ & $17 \%(2 / 12)$ \\
Conotruncal & $33 \%(4 / 12)^{*}$ & $0 \%(0 / 12)$ \\
Ventricular & $42 \%(5 / 12)$ & $17 \%(2 / 12)$ \\
Aortic arch defects & $0 \%(0 / 12)$ & $0 \%(0 / 12)$ \\
No defects & $25 \%(3 / 12)^{*}$ & $83 \%(10 / 12)$ \\
\hline
\end{tabular}

Percentage of affected embryos are indicated; absolute number of affected/ total embryos are also shown.

$* p<0.05$.

To investigate whether NCC were specified and migrated in antisense Ufd1-infected embryos, we examined two molecular markers, dHAND and neuropilin-1, both expressed in the NCC-derived mesenchyme of pharyngeal arches. Expression of dHAND (Fig. 5, H and I) and neuropilin-1 (data not shown) was relatively normal in the pharyngeal arches of $\mathrm{HH}$ stage 18 experimental embryos compared with controls. This result suggests that NCC become specified, migrate, and differentiate into mesenchymal cells during early pharyngeal development of antisense Ufd1l-infected embryos. Taken together, these data indicate that functional attenuation of Ufd1l in cardiac NCC leads to an increased incidence of conotruncal septal defects in chick embryos and these defects do not result from nonspecific cell death before NCC migration.

\section{DISCUSSION}

Cross-species analysis is sometimes useful in understanding potential causes of human disease. Mice homozygous for deletion of Ufd1l are early embryonic lethal, whereas mice heterozygous for a Ufdll mutation are normal, precluding an examination of whether Ufd1l plays a role in cardiac NCC development (16). Antisense nucleotides designed to hybridize to specific mRNA sequences have been used to attenuate the 
function of numerous genes both in vitro and in vivo, including developmentally regulated genes in chick embryos (22-24). By using a replication-incompetent retrovirus that has proved beneficial in studying the avian NCC lineage, we were able to introduce antisense Ufdll transcripts into chick cardiac NCC over long time spans and examine the role of Ufd11 in cardiac $\mathrm{NCC}$ in vivo.

Although functional attenuation of Ufd11 in NCC lineage resulted in an increased number of conotruncal septal defects in chick embryos, there was phenotypic variation. It is possible that the phenotypic variation may reflect the gene dosage effect of Ufd1l resulting from a variable efficiency of retroviral infection in each chick embryo. If this is the case, then conotruncal septation requires Ufd11 in a dose-sensitive manner in this chick model, although haploinsufficiency of Ufd1l alone is not sufficient for the septal defects in the mouse model. Alternatively, it may reflect allelic variability, variable penetrance caused by environmental factors, or stochastic events during embryonic development similar to that proposed in patients with 22q11DS. We cannot distinguish between these possibilities as it is not possible to examine effectively the level of attenuation of Ufd11 protein in premigratory NCC of embryos studied later in development for defects in cardiogenesis.

Recent genomic manipulations in mice have provided insight into potential roles of candidate genes for 22q11DS. Mice harboring a hemizygous deletion of 18 genes, including Ufd1l, that are deleted in patients with 22q11DS $(D f 1 /+)$ were generated and exhibit aortic arch malformations in $\sim 30 \%$ of cases (16). Further analyses determined that haploinsufficiency of Tbxl was responsible for aortic arch malformations in $D f 1 /+$ mice (10). Mice homozygous for the Tbxl mutation displayed craniofacial and cardiovascular defects similar to 22q11DS (9-11), suggesting that $T B X 1$ may be a major determinant of the phenotype of 22q11DS. However, TBXI mutations have not been identified in patients who have the $22 \mathrm{q} 11$ deletion phenotype and do not have del.22q11 $(10,13)$. In addition, $D f 1 /+$ mice have broader phenotypic features that have not been observed in mice heterozygous for a Tbxl mutation, including conotruncal and ventricular septal defect, hypoplasia of thymus and parathyroid glands, and signs of behavioral and psychiatric disorder $(16,25,26)$. These results indicate that haploinsufficiency of $T b x 1$ and additional genes in the $D f 1$ deletion region together contribute to the entire phenotype of $D f 1 /+$ mice. Our data in the present study suggest a role for Ufd11 in conotruncal development and thus support a possibility that Ufd1l may contribute to conotruncal and ventricular septal defects as a modifier gene in $D f l /+$ mice. Ufdll might also contribute to the hypoplasia of the thymus/parathyroid glands and behavioral/psychiatric phenotype of $D f l /+$ mice, because it is expressed in the developing pharyngeal structures and brain. The association of a promoter polymorphism of UFD1L with schizophrenia susceptibility has recently been reported (27). Definitive evaluation of Ufd1l's role in particular tissues awaits tissue-specific disruption of Ufdll in mice, currently being performed in our laboratory.

Although we determined that Ufd11 plays a role in cardiac NCC, cellular functions of Ufd11 in avian or mammalian cells remain to be studied. We speculate that Ufd11 is required for postmigratory differentiation of cardiac NCC in the conotruncal region because 1) the infection of retrovirus containing antisense Ufdll did not affect NCC survival and migration in primary NCC; 2) Ufd11 was expressed at high levels in the conotruncal region; and 3) functional attenuation of Ufd11 resulted in conotruncal septation defects, although the phenotype was milder than that observed after ablation of premigratory NCC in chick embryos. Recent biochemical studies demonstrated multiple functions of Ufd1, including the activation of membrane-bound transcription factors and transportation of proteins from the endoplasmic reticulum into the cytosol, by regulating ubiquitin/proteosome-dependent processing (2831). Identification of pathways affected by Ufd1l in cardiac NCC will be necessary to understand the mechanism through which Ufd11 regulates NCC development.

Acknowledgments. We thank T. Mikawa for proretroviral pCXIZ vector and members of the molecular pathology Core (C. Pomajzl, J. Shelton, and J. Richardson) for assistance of histologic analysis.

\section{REFERENCES}

1. Scambler PJ 2000 The 22q11 deletion syndromes. Hum Mol Genet 9:2421-2426

2. Driscoll DA, Budarf ML, Emanuel BS 1992 A genetic etiology for DiGeorge syndrome: consistent deletions and microdeletions of 22q11. Am J Hum Genet 50:924-933

3. Scambler PJ, Kelly D, Lindsay E, Williamson R, Goldberg R, Shprintzen R, Wilson DI, Goodship JA, Cross IE, Burn J 1992 Velo-cardio-facial syndrome associated with chromosome 22 deletions encompassing the DiGeorge locus. Lancet 339:1138-1139

4. Burn J, Takao A, Wilson D, Cross I, Momma K, Wadey R, Scambler P, Goodship J 1993 Conotruncal anomaly face syndrome is associated with a deletion within chromosome 22q11. J Med Genet 30:822-824

5. Ryan AK, Goodship JA, Wilson DI, Philip N, Levy A, Seidel H, Schuffenhauer S, Oechsler H, Belohradsky B, Prieur M, Aurias A, Raymond FL, Clayton-Smith J, Hatchwell E, McKeown C, Beemer FA, Dallapiccola B, Novelli G, Hurst JA, Ignatius J, Green AJ, Winter RM, Brueton L, Brondum-Nielsen K, Stewart F, Essen TV, Patton M, Paterson J, Scambler PJ 1997 Spectrum of clinical features associated with interstitial chromosome 22q11 deletions: a European collaborative study. J Med Genet 34:798-804

6. Kirby ML, Gale TF, Stewart DE 1983 Neural crest cells contribute to normal aorticopulmonary septation. Science 220:1059-1061

7. Kirby ML, Waldo KL 1995 Neural crest and cardiovascular patterning. Circ Res 77:211-215

8. Lindsay EA 2001 Chromosome microdeletions Dissecting del22q11 syndrome. Nat Rev Genet 2:858-868

9. Merscher S, Funke B, Epstein JA, Heyer J, Puech A, Lu MM, Xavier RJ, Demay MB, Russell RG, Factor S, Tokooya K, Jore BS, Lopez M, Pandita RK, Lia M, Carrion D, Xu H, Schorle H, Kobler JB, Scambler P, Wynshaw-Boris A, Skoultchi AI, Morrow BE, Kucherlapati R 2001 TBX1 is responsible for cardiovascular defects in velocardio-facial/DiGeorge syndrome. Cell 104:619-629

10. Lindsay EA, Vitelli F, Su H, Morishima M, Huynh T, Pramparo T, Jurecic V, Ogunrinu G, Sutherland HF, Scambler PJ, Bradley A, Baldini A 2001 Tbx1 haploinsufficiency in the Di George syndrome region causes aortic arch defects in mice. Nature 410:97-101

11. Jerome LA, Papaioannou VE 2001 Di George syndrome phenotype in mice mutant for the T-box gene, Tbx1. Nat Genet 27:286-291

12. Wadey R, McKie J, Papapetrou C, Sutherland H, Lohman F, Osinga J, Frohn I, Hofstra R, Meijers C, Amati F, Conti E, Pizzuti A, Dallapiccola B, Novelli G, Scambler P 1999 Mutations of UFD1L are not responsible for the majority of cases of DiGeorge Syndrome/velocardiofacial syndrome without deletions within chromosome 22q11. Am J Hum Genet 65:247-249

13. Gong W, Gottlieb S, Collins J, Blescia A, Dietz H, Goldmuntz E, McDonald-McGinn DM, Zackai EH, Emanuel BS, Driscoll DA, Budarf ML 2001 Mutation analysis of TBX1 in non-deleted patients with features of DGS/VCFS or isolated cardiovascular defects. J Med Genet 38:E45

14. Pizzuti A, Novelli G, Ratti A, Amati F, Mari A, Calabrese G, Nicolis S, Silani V, Marino B, Scarlato G, Ottolenghi S, Dallapiccola B 1997 UFD1L, a developmentally expressed ubiquitination gene, is deleted in CATCH 22 syndrome. Hum Mol Genet 6:259-265

15. Yamagishi H, Garg V, Matsuoka R, Thomas T, Srivastava D 1999 A molecular pathway revealing a genetic basis for human cardiac and craniofacial defects. Science 283:1158-1161

16. Lindsay EA, Botta A, Jurecic V, Carattini-Rivera S, Cheah YC, Rosenblatt HM, Bradley A, Baldini A 1999 Congenital heart disease in mice deficient for the DiGeorge syndrome region. Nature 401:379-383 
17. Hyer J, Mikawa T 1997 Retroviral techniques for studying organogenesis with a focus on heart development. Mol Cell Biochem 172:23-35

18. Garg V, Yamagishi C, Hu T, Kathiriya IS, Yamagishi H, Srivastava D 2001 Tbx1, a Di George syndrome candidate gene, is regulated by sonic hedgehog during pharyngeal arch development. Dev Biol 235:62-73

19. Bergwerff M, Verberne ME, DeRuiter MC, Poelmann RE, Gittenberger-de Groot AC 1998 Neural crest cell contribution to the developing circulatory system: implications for vascular morphology? Circ Res 82:221-231

20. Poelmann RE, Mikawa T, Gittenberger-de Groot AC 1998 Neural crest cells in outflow tract septation of the embryonic chicken heart: differentiation and apoptosis. Dev Dyn 212:373-84

21. Kunte A, Ivey K, Yamagishi C, Garg V, Yamagishi H, Srivastava D 2001 A common cis-acting sequence in the DiGeorge critical region regulates bi-directional transcription of UFD1L and CDC45L. Mech Dev 108:81-92

22. Farrell MJ, Stadt H, Wallis KT, Scambler P, Hixon RL, Wolfe R, Leatherbury L, Kirby ML 1999 HIRA, a DiGeorge syndrome candidate gene, is required for cardiac outflow tract septation. Circ Res 84:127-135

23. Isaac A, Sargent MG, Cooke J 1997 Control of vertebrate left-right asymmetry by a Snail-related zinc finger gene Science 275:1301-1304

24. Lallier T, Bronner-Fraser M 1993 Inhibition of neural crest cell attachment by integrin antisense oligonucleotides. Science 259:692-695
25. Taddei I, Morishima M, Huynh T, Lindsay EA 2001 Genetic factors are major determinants of phenotypic variability in a mouse model of the DiGeorge/del 22q11 syndromes. Proc Natl Acad Sci U S A 98:11428-11431

26. Paylor R, McIlwain KL, McAninch R, Nellis A, Yuva-Paylor LA, Baldini A, Lindsay EA 2001 Mice deleted for the DiGeorge/velocardiofacial syndrome region show abnormal sensorimotor gating and learning and memory impairments. Hum Mol Genet 10:2645-2650

27. De Luca A, Pasini A, Amati F, Botta A, Spalletta G, Alimenti S, Caccamo F, Conti E, Trakalo J, Macciardi F, Dallapiccola B, Novelli G 2001 Association study of a promoter polymorphism of UFD1L gene with schizophrenia. Am J Med Genet 105:529-533

28. Meyer HH, Shorter JG, Seemann J, Pappin D, Warren G 2000 A complex of mammalian ufd1 and npl4 links the AAA-ATPase, p97, to ubiquitin and nuclear transport pathways. EMBO J 19:2181-2192

29. Hoppe T, Matuschewski K, Rape M, Schlenker S, Ulrich HD, Jentsch S 2000 Activation of a membrane-bound transcription factor by regulated ubiquitin/ proteosome-dependent processing. Cell 102:577-586

30. Rape M, Hoppe T, Gorr I, Kalocay M, Richly H, Jentsch S 2001 Mobilization of processed, membrane-tethered SPT23 transcription factor by CDC48 (UFD1/NPL4), a ubiquitin-selective chaperone. Cell 107:667-677

31. Ye Y, Meyer HH, Rapoport TA 2001 The AAA ATPase Cdc48/p97 and its partners transport proteins from the ER into the cytosol. Nature 414:652-656 